\title{
Blogging by South African academic librarians: a preliminary survey
}

\section{Janine Dunlop}

Janine Dunlop

Librarian, Manuscripts and Archives

University of Cape Town

Janine.dunlop@uct.ac.za

\section{Abstract}

Blogging in South African academic libraries is a relatively new phenomenon. At the time of writing, 28 blogs had been authored by South African academic librarians. A study was conducted of these blogs to establish who these bloggers are and why they are blogging. Several have an experimental air to them. Not all the blogs studied are active and not all have a clear aim or idea of who their audience should be. The most effective blogs seem to be those that invite comments and provide commentary on posts, rather than disabling comments and merely providing links to articles or information.

\section{Introduction and literature survey}

The University of Pretoria Education Library hosted an exhibition of stories written by students of Early Education.' Stellenbosch University Library wants to know whether their patrons find RefWorks useful. ${ }^{2}$ The University of Johannesburg is ranked 3704 th, according to the World Universities Ranking on the Web. ${ }^{3}$ All this information comes from blogs authored by librarians in South African academic libraries.

The word 'blog', derived from 'web log', is the term for an online journal that contains entries in reverse chronological order. Blogs, together with tools like flickr, ${ }^{4}$ Facebook ${ }^{5}$, del.icio.us ${ }^{6}$ and others, together form what is known as web 2.0 or 'the social web', which is a new way of using the internet. Whereas before, web sites were fairly static and content was generated only by web designers and web site owners, Web 2.0 brings interactivity and collaboration 
into the mix. Web site readers and users are now able to comment on and participate in the creation of sites.

'Library $2.0^{\prime}$ ' is a term that emerged from Web 2.0 and is used to denote a shift in the way libraries serve their users. Library 2.0 seeks to push information out to users and enables user participation in the organisation of information. For example, social tagging, that is allowing users to add keywords, or 'tags' to items in the library catalogue, is one way in which Library 2.0 is employed. Blogs, therefore, can be used by librarians as a method of pushing information out to users and allowing them to contribute by means of comments.

Most of the literature on the topic of academic library blogging emanates from countries other than South Africa. Recently, a posting ${ }^{7}$ was made to LibWorld by van Wyk (2009), examining the phenomenon of library blogging generally in South Africa, but no research has been conducted on South African academic library blogging.

An early study conducted by Clyde (2004) was done on all library blogs that were in existence at the time. It was found that library blogs originated from only three countries, with the majority in the United States. Since then, blogging and specifically academic library blogging has become far more widespread. This is evidenced by Lihitkar and Yadav's (2008) study of ten university library blogs from both India and the United States.

Blogs are being used by academic librarians for various purposes. Shrecker's study (2008) examined three blogs in academic libraries in order to establish various uses for blogs in libraries. She found that blogs can enhance a library's web presence, and provide opportunity for conversation and communication. Goodfellow and Graham's (2007) paper confirms this: by establishing a blog about a conference they attended, they were able to maintain contact with colleagues at home and keep them engaged with and involved in what was happening at the conference. Barton and Wesmantel's (2006) study reports on the use of a blog as a record for reference queries. Another study done on academic library blogs is that of Draper and Turnage (2008), who explore the medium as a library marketing tool, and conclude that while blogs may be effective in this sphere, they in turn have to be marketed in order to fulfil this role. More recent accounts include those by Chen (2009), which reports on the use of a blog to enhance performance in the cataloguing department of an academic library, and Oxford (2009), which examines the use of Web 2.0 tools such as blogging in academic liaison. 
Several South African academic librarians are blogging and some have been active since 2005 . No study has been done on how many academic library blogs exist in South Africa and what content they generate. The questions therefore arise: Why are South African academic librarians blogging? What are they using the medium for? Who are they talking to and are they being heard? Are blogs an appropriate medium to use to reach users? This paper attempts to answer these questions. Finding the answers would provide a basis for decision making for other librarians who are considering using blogging as a means of communicating with their patrons. It is also hoped these answers will provide a summary of what constitutes an effective blog and therefore help future bloggers to make considered choices about how to use the medium.

\section{Methodology}

All existing blogs emanating from South African academic libraries were sought for this study. At the time of writing (October 2009), there were 28 blogs authored by South African academic librarians. Four methods were used to find relevant blogs. A message was sent to the LIASA (Library and Information Association of South Africa) listserv, requesting feedback from those who authored blogs and those who knew of blogs maintained by South African academic librarians. Four responses were received, some including links to blogs, while others referred the author to possible sources of information.

Blogs were also sought by searching the internet, using various combinations of the keywords, 'South Africa', 'South African', 'weblog', 'web log', 'blog', 'librarian' and 'library'. The web pages of all South African academic libraries were searched in order to establish whether there was a link to a blog from the main page or that of the branch library sites. Finally, word of mouth served as a means of establishing which blogs are in existence.

For each of the blogs, the following aspects were examined and recorded in a spreadsheet:

1. When established;

2. Frequency of posting;

3. Level of interactivity (number of posts relative to number of comments);

4. Author (individual or institutional);

5. 'About' page;

6. Audience (intended, in the About page or elsewhere, or implied);

7. Visible usage statistics (on 9 September 2009); 

8. Links to other sites;
9. Other interesting aspects.

\section{Findings}

How many blogs are there?

It was established that there are 28 blogs that originate from academic libraries in South Africa. Of these, two were inaccessible, one due to maintenance being conducted on the University web page and the other due to the fact that the blog was established for a particular purpose, and is no longer in use.

How long have they been around?

The oldest blog was established in April 2005. Another blog was started in August of the same year. Eight were started in 2006, nine in 2007 and eight in 2008.

How often do they post?

For this study, it was decided that an active blog was one in which the last post or entry was no more than two months old as at 9 September 2009 . Using this definition, 12 of the 28 blogs were active.

On average, these 12 blogs have been in existence for 33 months and the average number of posts on each is 398 . The number of posts per month varied by author of the blog is and the subject.

Who are the authors?

Of the existing blogs, 27 originate from six academic institutions: Rhodes University (1), the University of Cape Town (9), the University of Johannesburg (5), the University of Kwazulu-Natal (2), the University of Pretoria (9) and the University of Stellenbosch (1). The remaining one is a group blog authored by the Research Libraries Consortium, that is the University of Cape Town, the University of the Witwatersrand and the University of Kwazulu-Natal (see Figure 1 below).

\section{Do readers comment?}

The number of comments received on the 12 blogs is negligible: the highest number of comments on any of the blogs is five. Seven of the blogs had received no comments at all. It should be taken into account, however, that two of the blog authors from the University of Cape Town Libraries mentioned that 


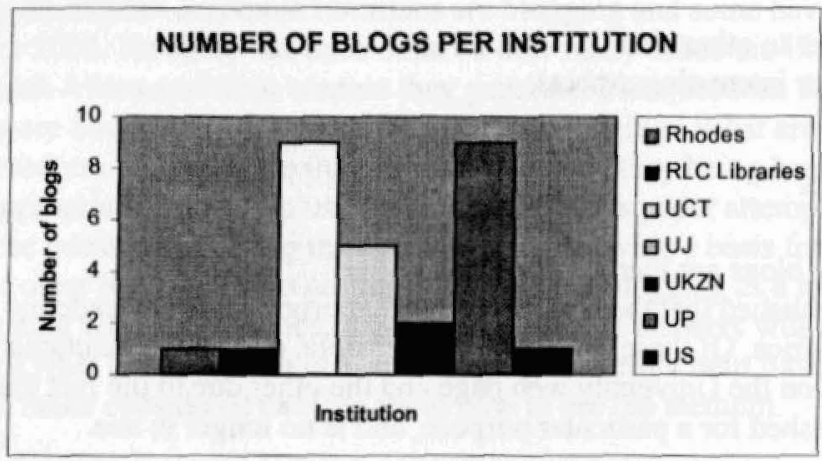

Figure 1: Number of blogs per institution

they had turned their comments facility off following the receipt of too much spam. This study did not examine whether other blog authors had done this.

What are the blogs about?

Of the 28 blogs, 16 have a stated aim, either as a paragraph under the blog title, or on a separate 'About' page. Two are general library blogs, which originate from the main library. Two are blogs about new books that have been acquired by the library. Twelve are authored by subject librarians or librarians in subject specialist libraries who seek to inform their users of events and resources in the library. Six are by librarians seeking to communicate with their colleagues about library-related issues. Of the rest, there is one that was established purely to test and make available a podcast and another a library catalogue widget, one that aimed to help students with a specific course, one on a specific topic related to libraries and publishing, one that invites suggestions for library service and one that is a personal blog authored by a librarian, providing links to material on various topics such as technology, libraries, information literacy and the internet.

Who are they talking to?

The blogs were examined to establish who the intended or implied audience was. It was discovered that 17 of the 28 blogs are aimed at library patrons, four are aimed only at librarians and one at both library patrons and librarians. For six of the existing blogs, it is unclear who the audience is intended to be. This lack of clarity stems from the fact that there seems to be no pattern or consistency to the type of entries posted: some entries are targeted at colleagues and others at library patrons. Those that target library patrons contain information about new facilities and resources in the library, and library opening hours. Some alert users to new online publications in a specific field. 
Those blogs that are aimed only at librarians vary in their effectiveness. While it is problematic to define efficacy, this study looked at whether there was a stated aim and whether the blog had managed to achieve this. It appears that only one of the four has managed to achieve its objective. This was to "share information and knowledge to enhance our services". It was started in October 2007 and is a well-maintained, content-rich blog that shares information about events in the library world, new technologies that can help enhance services and information from other library blogs.

Two out of the four have been less effective by this definition. One aims to be "a space where all library staff involved can participate in conversations about setting up and managing a Research Commons". However, it boasts only two posts and there are no comments from readers. It is speculated that perhaps this blog was established too prematurely for any meaningful conversation to take place, as none of the libraries in the Research Libraries Consortium had opened their Research Commons at the time. The other blog aims "to create a space for discussing and sharing library related matters". However, it diverts from this aim, as one of the posts advertises library instruction and seems to be aimed at library patrons. It also contains only three posts and no reader comments. The fourth blog has no stated aim and seems to be an internal blog for library staff who are involved in setting up a multimedia centre within the library. It contains information about multimedia centres in other South African academic libraries.

The only blog explicitly aimed at both library patrons and librarians was established in 2006 and states that part of its aim is to provide an opportunity for colleagues to explore the new technology of blogging and perhaps to set up blogs of their own.

How often are they read?

For the purposes of this study, it was decided to examine only visible statistics of visits to the blogs. The cut-off date chosen was 9 September 2009. Of the 28 blogs, only four displayed their statistics: one from the University of Pretoria and three from the University of Johannesburg. The latter three blogs had been active for between 16 and 23 months and their total visitor statistics averaged 2,685 . The former blog had been active for 29 months and had been visited 23,696 times.

What other features are available?

Blogs in any sphere, whether business or personal, commonly include such features as personalisation and the blogroll, which is a list of links to other sites. Generally, these links point blog readers to sites that focus on a similar topic, or are related in some way to the content of the site. Of the 28 blogs studied, 
seven include links to other sites. Other interesting features on some of the blogs include widgets that provide headlines from other blogs, RSS feeds for specific categories of posts, a downloads page of $p d f$ documents on the topic being blogged about, tag clouds, a photo gallery, links to library journals and links to other resources. One blog offers a list of Library 2.0 sites to which the author subscribes, such as Twitter, Facebook, del.icio.us and LibraryThing.

\section{Comment}

From this study, it is evident that South African academic librarians are blogging in order to communicate firstly with their patrons and secondly with their colleagues. Given that the longest-standing blog in academic libraries in South Africa is four years old, it can be said that blogging in this sphere is a relatively new phenomenon. This fact would account for an observation that was made during this study that five of the blogs have an 'experimental' air to them. It is speculated that the authors were experimenting with the technology and started a blog without having a clear idea about what the aim of the blog should be and to whom they should be talking.

It is of interest that none of the blog authors who provide links to content within a specific academic field comment on or include their opinion on the material to which they are linking. This is perhaps an area where South African academic librarian bloggers could grow and develop their own voices.

Returning to the literature reviewed earlier, one can see that South African academic blogs still have a way to go in using blogging as an effective communication tool. If, as Shrecker (2008: 127) states, blogs provide an opportunity for conversation, then it could be said that South African academic library bloggers are not yet at that point. Comments are few and far between and comment facilities have been turned off in some cases. Further, there has been no South African academic library blog to date that has been started with the specific aim of keeping in contact with colleagues during a conference or workshop as discussed by Goodfellow and Graham (2007).

It is noteworthy that of the 23 tertiary education institutions in South Africa, only six have produced library blogs. Also significant is that all of the six blogging university libraries are at previously advantaged institutions. Could this be because of better resources in these institutions, such as access to computers, and more staff? This question could provide the basis for a further study. 


\section{Conclusion}

Blogging by academic librarians has enormous potential for communicating with library patrons, reaching new patrons and advertising library services. While some South African academic librarians have begun to take up the challenge of blogging, it is hoped that in the future, there will be even more blogging across more institutions and on more topics.

There are a number of aspects that require further study. The first is that of marketing of academic library blogs in South Africa. If blogs are there to communicate with library patrons and reach new patrons, then how are these patrons to be made aware of the existence of these blogs? Are RSS feeds made available to blog readers? Are blogs being advertised on the library's home page?

Another is an investigation of the need for blogging in South African academic libraries. Since this study did not take into account all statistics of all the blogs, a valuable study would be an examination of the visitor statistics to the blogs and a survey of the readers of these blogs to establish whether the content is useful to them.

The final aspect is that of the concept of interactivity and conversation. By encouraging comments and trackbacks, blogs are by nature interactive. A useful investigation would be the ways in which to engage South African academic library blog readers and encourage feedback through these blogs.

\section{References}

Barton, Emily and Arlene Wesmantel. 2006. Reflogs now: internal web logs can rejuvenate reference. Library journal October 1: 28-30.

Chen, Sherab. 2009. Can blogging help cataloging?: Using a blog and other Web 2.0 tools to enhance cataloging section activities. Library resources and technical services 53(4): 251-260.

Clyde, Laurel A. 2004. Library weblogs. Library management 25(4/5): 183 189.

Draper, Lani and Marthea Turnage. 2008. Blogmania: blog use in academic libraries. Internet reference services quarterly. 13(1): 15-55. 
Education Library Blog @ University of Pretoria.

http://edulibpretoria.wordpress.com/2007/1 1/14/new-scanning-workstation-inlibrary/ Accessed 15 July 2009.

Goodfellow, Tom and Sarah Graham 2007. The blog as a high-impact institutional communication tool. The electronic library. 25(4): 395-400.

Library Suggestion Blog. http://sulibrary.blogspot.com/ Accessed 15 July 2009.

Lihitkar, Shalini and Meena Yadav. 2008. A study of university libraries weblogs: online tool for information sharing and dissemination. SRELS journal of information management $45(1)$ : 17-36.

Oxford, Sarah. 2009. Being creative with Web 2.0 in academic liaison. Library and information update 8(5): 40-41.

Shrecker, Diane L. 2008. Using blogs in academic libraries: versatile information platforms. New library world 109(3/4): 117-129.

\section{UJ Science Librarian Blog.}

http://ujsciencelibrarianblog.blogspot.com/search?q=world+universities+rankin g. Accessed 15 July 2009

Van Wyk, Johan. http://infobib.de/blog/2009/06/08/libworld-south-africa. Accessed 21 October 2009.

\section{Endnotes}

1 http://edulibpretoria.wordpress,com/2009/03/31/story-writing-exhbition-atuniversity-of-pretorias-education-libraryl

${ }^{2}$ http://sulibrary.blogspot.com/2008/07/what-is-your-view-on-value-of-refworks.html

${ }^{3} \mathrm{http}: /$ ujsciencelibrarianblog.blogspot.com/search?q=world+universities+ranking

${ }^{4}$ http://www.flickr.com

5 http://www.facebook.com

6 http://delicious.com

7 http://infobib.de/blog/2009/06/08/libworld-south-africa/\#footnote-link-8-1983 